\title{
ANAESTHETIC MANAGEMENT OF ARTERIOVENOUS MALFORMATIONS OF THE VEIN OF GALEN
}

\author{
M.E. MCLeOd, R.E. Creighton and R.P. Humphreys
}

\begin{abstract}
Arteriovenous malformations of the vein of Galen, though rare, are associated with a significant mortality. The anaesthetic management of patients with this defect during surgery may be complicated by massive blood loss and congestive heart failure. Four patients under 18 months of age underwent craniotomies for arteriovenous malformations of the vein of $\mathrm{Galen}$. Since two required a second craniotomy for ligation of residual feeding vessels, there were six procedures in the four patients. Average blood loss per procedure was estimated at 126 per cent of blood volume. One patient died during operation and one had an intra-operative cardiac arrest. Both of these patients had associated cardiac failure. In the presence of a compromised myocardium, sudden blood loss or attempts at induced hypotension may result in inadequate diastolic perfusion of the heart and precipitate cardiac arrest. Consequently, these patients should be maintained in a euvolaemic state with transfusion and attempts at controlled hypotension should be avoided.
\end{abstract}

KEY WORDS: SuRGERY, Cerebral Arteriovenous Malformation, vein of Galen; Anaesthetic Management.

Cerebral arteriovenous malformation (AVM) involving the great vein of Galen is rare, but nevertheless represents a significant proportion of AVMs presenting in infancy. Knudson and Alden reported that 52 of 81 patients less than six months of age who had central nervous system arteriovenous malformations had lesions involving the vein of Galen. ${ }^{1}$

The great cerebral vein of Galen is formed by the union of the internal cerebral and basal veins behind the splenium of the corpus callosum. It then runs backward and empties into the straight sinus. AVMs of the vein of Galen involve direct communications from the carotid or vertebral arterial systems, or both. Signs and symptoms of these malformations may be local, either from compression of brain tissue or from obstruction of CSF flow, or systemic as a result of cardiovascular decompensation.

The age at presentation is related to the size of the lesion. Patients can be divided into four

M.E. McLeod M.D., F.R.C.P.(C), Clinical Fellow and R.E. Creighton M.D., F.R.C.P.(C), Staff Anaesthetist and Associate Professor, Deparment of Anaesthesia; R.P. Humphreys M.D., F.R.C.S.(C), Staff Neurosurgeon and Associate Professor of Surgery; The Hospital For Sick Children and The University of Toronto, Toronto, Ontario.

Address for Reprints: Dr. R.E. Creighton, Department of Anaesthesia, The Hospital For Sick Children, 555 University Avenue, Toronto, Ontario M5G 1 X8.

Can. Anaesth. Soc. J., vol. 29, no. 4, July 1982 groups according to age and clinical features. ${ }^{2-5}$ The neonatal group has the poorest prognosis.

Patients in the first or neonatal group present in the first few days of life with severe congestive heart failure and frequently a cranial bruit. Although surgery is the definitive mode of treatment, many of these patients die of their cardiovascular complications before operative therapy can be undertaken. In the review of Amacher and Shillito, ${ }^{2}$ ten of eleven cases were not diagnosed until post-mortem examination.

The second group of patients presents in infancy with craniomegaly and an associated cranial bruit. They are usually found to have mild heart failure.

Patients in the third group present later in infancy. They tend to have craniomegaly and a cranial bruit but no evidence of heart failure.

A fourth group has also been described in whom the presenting complaints are headache and exercise syncope. A calcified rim may be seen in the pineal region in these patients who present in childhood or early adult life. ${ }^{6}$

The first two groups have received most attention in the literature, both from a neurological and from a cardiac point of view. These patients also present the greatest challenge in anaesthetic management. In this paper we discuss our recent experience in anaesthetic management of four patients with vein of Galen 
AVMs who underwent a total of six craniotomies.

\section{Patients AND Methods}

In 1980, four patients (three males, one female) with vein of Galen AVMs considered surgically correctable were referred to the neurosurgical unit at The Hospital for Sick Children, Toronto. Two were in the neonatal group, one was in group two, and one was in group three. The youngest patient was 14 days old at craniotomy and the oldest $17 \frac{1}{2}$ months (Table I).

Diagnosis in all cases was made by clinical examination and computed axial tomography, followed by four-vessel cerebral angiography to identify all vessels feeding the AVM. Thus, all patients had had one general anaesthetic (for angiography) without complication before craniotomy.

\section{Anaesthetic Management}

All patients were assessed pre-operatively by the cardiology service and those with congestive heart failure were treated medically before operation.

A large bore intravenous line was started in all cases because of the potential for rapid blood loss requiring transfusion. In all but one of the six craniotomies a peripheral arterial catheter was used to monitor arterial pressure and blood gas tensions. The electrocardiogram and patient temperature were also monitored continuously and a warming blanket was used to reduce heat loss. Intermittent positive pressure ventilation was used in all patients to maintain a $\mathrm{PCO}_{2}$ of $3.3-4.0 \mathrm{kPa}(25-30 \mathrm{mmHg})$. Furosemide 0.5 $\mathrm{mg} \cdot \mathrm{kg}^{-1}$ body weight to reduce brain bulk and dexamethasone to minimize cerebral oedema were given intravenously at induction.

Blood loss was estimated on the basis of haemoglobin concentrations pre-operatively and 24 hours post-operatively and the amount of

TABLE I

Age Distribution of Patients

\begin{tabular}{cccc}
\hline Case number & Sex & \multicolumn{2}{c}{ Age at operation } \\
\hline 1 & $\mathrm{~F}$ & & 14 days \\
2 & $\mathrm{M}$ & $1 \mathrm{st}$ & $9 \frac{1}{2}$ months \\
& & $2 \mathrm{nd}$ & $11 \frac{1}{2}$ months \\
3 & $\mathrm{M}$ & & $17 \frac{1}{2}$ months \\
4 & $\mathrm{M}$ & $15 \mathrm{st}$ & 15 days \\
& & 2nd & 5 months \\
\hline
\end{tabular}

blood transfused. The results were expressed as a percentage of the estimated blood volume. ${ }^{7}$ Case 1 was excluded from these calculations as no post-operative haemoglobin value was available.

\section{Outcome}

There were three major complications in the six craniotomies, one resulting in intra-operative death (case 1). One patient (case 2) had a cardiac arrest during operation but was successfully resuscitated and one patient (case 4 ) had a brief period of hypotension during his second craniotomy.

Blood loss during the procedure ranged from 44-257 per cent of estimated blood volume with a mean of 126 per cent (Table II). Fresh frozen plasma was given with packed cells in order to transfuse the equivalent of whole blood. No coagulopathy was encountered with these massive transfusions.

Two of the survivors were available for follow-up and both had some residual neurological deficit. Repeat angiography of case 4 showed incomplete obliteration of the malformation.

\section{Case 1}

A female infant born at 40 weeks gestation experienced breathing difficulties with feeding shortly after birth but was not cyanotic. Chest $\mathrm{x}$-ray showed cardiomegaly and electrocardiography gave evidence of biventricular hypertrophy. She was started on digoxin and a diuretic and was transferred to our hospital at the age of one week with a respiratory rate of 120 /minute, heart rate of 180 beats/minute, an $S_{3}$ and a grade II/VI systolic ejection murmur.

Cerebral angiography demonstrated a large Galen AVM. A craniotomy was done when she was 14 days old. Before operation her haemoglobin was $17.9 \mathrm{~g} / 100 \mathrm{ml}$ and her weight was $2190 \mathrm{~g}$.

She was intubated awake and anaesthesia was then induced with a mixture of nitrous oxide and

TABLE II

Blood Loss During SURgery

\begin{tabular}{ccc}
\hline \hline Case number & Surgery & $\%$ Blood volume lost \\
\hline 2 & 1st procedure & 257 \\
& 2nd procedure & 191 \\
3 & & 44 \\
4 & 1st procedure & 97 \\
& 2nd procedure & 43 \\
\hline
\end{tabular}


oxygen and trichloroethylene 0.2 per cent. $D$. tubocurarine was used for muscle relaxation. Three hours and forty-five minutes after induction, she abuptly became bradycardic and hypotensive in association with a sudden loss of blood. She responded to closed chest massage, cardiotonic dnigs and transfusion, and stabilized with a blood pressure of $18.6-21.3 \mathrm{kPa}$ (140$160 \mathrm{mmHg}$ ) systolic. However, after twenty minutes, hypotension and bradycardia recured and progressed to ventricular fibrillation. She could not be resuscitated. A total of 500 mil of blood had been transfused to keep up with losses (270 per cent of estimated blood volume) during the procedure.

Post-mortem examination showed biventricular cardiac hypertrophy. The right ventricle and a papillary muscle showed evidence of infarction which was more then 48 hours old. There was also extensive subendocardial banding necrosis and bilateral pulmonary oedema.

\section{Case 2}

A $9 \frac{1}{2}$ month old male infant presented with craniomegaly $(>98$ th percentile) and a cranial buit. Mild congestive heart failure was also noted and he was started on oral digoxin. An electrocardiogram showed LAH, LVH, and RBBB. Cerebral angiography was done under general anaesthesia without complications (Figures 1 and 2) Subsequently this patient underwent a right fronto-parietal craniotomy. The procedure lasted eight hours and 45 minutes. Anaesthesia was induced with atropine, pancuronium, and thiopentone and maintained with nitrous oxide and oxygen, fentanyl and Innovar . Low concentrations of halothane and trichloroethylene were used during positioning and surgical preparation. A radial artery line was inserted percutaneously. The patient was maintained slightly hypovolaemic at a blood pressure of $10.6 / 6 \mathrm{kPa}(80 / 45 \mathrm{mmHg}$ ).

Two hours after induction his arterial pressure fell to $6.612 .7 \mathrm{kPa}(50 / 20 \mathrm{muH})$ and he had bradycardia. These changes were associated with rapid blood loss. The hypotension rapidly progressed to ventricular fibrillation despite aggressive transfusion. He was suecessfully resuscitated and remained stable throughout the remaining six hours of the operation. During the procedure $1500 \mathrm{ml}$ of blood was transfused. Estimated blood loss was 257 per cent of blood volume.

Only the right-sided feeders of the AVM ware obliterated at the first procedure. Consequently,

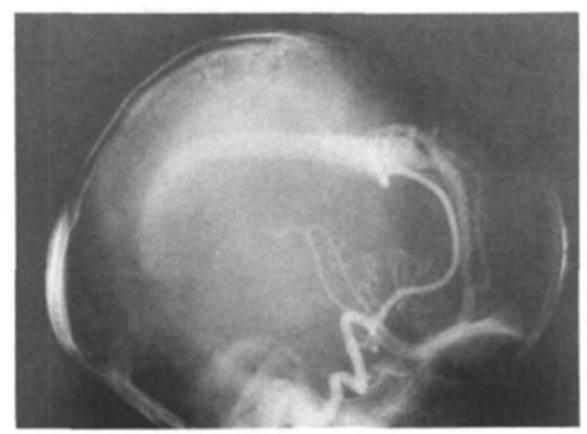

Froure 1 Carotid arteriogram of Case 2 showing arterior feeding vessels of the vein of Galen AVM.

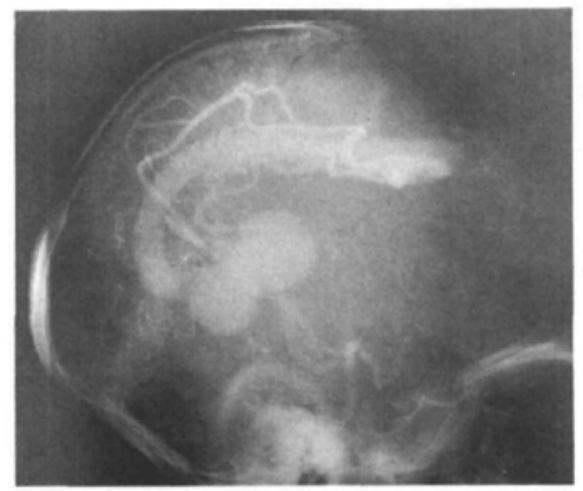

Froure 2 Vertebral arteriogram of Case 2 showing posterior feeding vessels of AVM.

the patient underwent a further operation two months later. Induction and maintenance were carried out as before, but no attempt was made to lower the arterial pressure below $13.3 \mathrm{kPa}$ $(100 \mathrm{mmHg})$ systolic. The remaining feeders were successfully elipped without complication. Blood loss during the second procedure was estimated at 191 per cent of blood volume.

At follow-up five months later, he was developing normally but had some residual spastic weakness on the left and increased tone and reflexes on the right.

\section{Case 3}

A $17 \frac{1}{2}$ month old male who had a heart murmur at birth was thought to have a patent ductus arteriosus. This murmur disappeared by three months of age and there were no further cardiac problens. At nine months, he was noted to have a large head and a diagnosis of obstructive hydrocephalus secondary to a vein of Galen 
AVM was made. Subsequently he required a ventriculo-peritoneal shunt to control the hydrocephalus. At 17 months he was referred to our hospital for further management. There was no clinical evidence of heart failure at this time and his electrocardiogram was within normal limits. Arteriography was done under general anaesthesia without complication and the lesion appeared surgically correctable.

He was then prepared for craniotomy. Anaesthesia was induced with thiopentone, pancuronium, and Innovar ${ }^{\infty}$. A dorsalis pedis arterial line and a 16 gauge intravenous line were inserted. Anaesthesia was maintained with nitrous oxide and oxygen, halothane 0.5 per cent, fentanyl and pancuronium. Blood pressure was stable at $13.3-16 \mathrm{kPa}(100-120 \mathrm{mmHg})$ systolic throughout the procedure which lasted seven hours and 45 minutes. Blood loss was estimated at 44 per cent of blood volume. No complications were encountered in the peri-operative period.

\section{Case 4}

A full term male infant showed evidence of respiratory distress shortly after birth. He had a hyperdynamic cardiac apex and a grade IIVVI systolic ejection murmur. Chest $x$-ray showed cardiomegaly and there was electrocardiographic evidence of right ventricular hypertrophy (Figure 3). Digoxin and furosemide therapy was started on the fifth day of life to control his heart failure. A cranial bruit was noted and cerebral angiography was done. This showed a vein of Galen AVM with feeders from the posterior cerebral arteries and the right anterior choroidal artery (Figure 4). At age fifteen days this patient underwent a craniotomy and the right-sided feeders were ligated.

Anaesthesia was induced as in the previous case. No hypotensive agents were used. Anaesthesia was maintained with pancuronium and a mixture of nitrous oxide and oxygen. No cardiovascular instability was encountered. Blood loss during the six hour procedure was estimated at 97 per cent of total blood volume.

A second craniotomy was done for ligation of the feeders on the left side when the patient was five months old. At this time the chest $\mathrm{X}$-ray still showed cardiomegaly but failure was well controlled with digoxin. Blood loss during the second operation was approximately 43 per cent of total blood volume.

Anaesthesia was induced with thiopentone, succinylcholine, and atropine. Nitrous oxide and

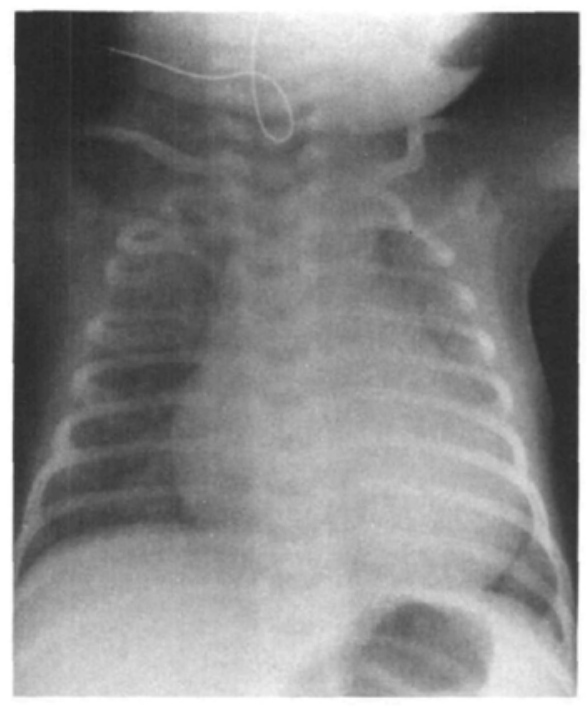

Figure 3 Pre-operative chest $x$-ray of Case 4 showing cardiomegaly and pulmonary vascular congestion.

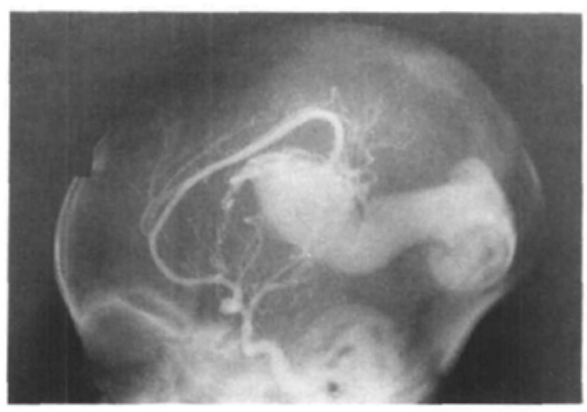

Figure 4 Carotid arteriogram of Case 4 demonstrating anterior feeders of vein of Galen AVM.

oxygen, halothane 0.5 per cent, fentanyl and d-tubocurarine were used for maintenance of anaesthesia.

Immediately before the procedure was completed and following transfusion of $150 \mathrm{ml}$ of blood, the patient became hypotensive with a pressure of $4.65 \mathrm{kPa}(35 \mathrm{mmHg}$ ) systolic but was quickly resuscitated. Eleven days postoperatively he required the insertion of a ventriculoperitoneal shunt. At follow-up one month after operation there was some residual weakness in the left hand. Repeat angiography showed incomplete obliteration of the AVM. 


\section{Discussion}

Due to the size and location of these malformations, blood loss can be considerable and may occur suddenly. Our patients lost from 44 to 257 per cent of their estimated total blood volume during craniotomy. Under these circumstances it is difficult to maintain a normal circulating blood volume and body temperature. The larger mal formations are associated not only with a greater likelihood of massive bleeding but also with congestive heart failure, placing such patients at even greater risk.

The aim of the anaesthetic management, therefore, is to maintain cardiovascular stability in the face of rapid changes in circulating volume and pre-existing myocardial disease. Jedeikin and his associates of the Division of Cardiology of The Hospital for Sick Children, Toronto, (unpublished observations) have confirmed that actual myocardial damage occurs in these patients. In a review of neonates dying of cerebral arteriovenous malformations, they found subendocardial pathological changes in seven of ten hearts. Areas of subendocardial necrosis and two areas of infarction were noted at autopsy in our first case.

Cardiopulmonary bypass with profound hypothermia has been suggested as a means of reducing blood loss and has been reported to be successful in the operative management of a vein of Galen AVM. ${ }^{8}$ In the neonatal age group, however, feeding vessels tend to be numerous and the use of this technique at our institution in two neonates was associated with catastrophic blood loss and intra-operative death. ${ }^{9}$

A second approach is the use of hypotensive agents to minimize blood loss and preven sudden volume changes which could compromise the myocardium. An argument in favour of hypotension and relative hypovolaemia is that the heart, which is accustomed to a low resistance run-off through the AVM, will be less likely to fail after the feeding vessels are clipped if the volume state is low. Takehara, et al. in their report of a single case, recommended that the patient be kept hypovolaemic before clipping to prevent circulatory overload when the systemic vascular resistance rises. ${ }^{10}$

Our experience with case 2 , however, leads us to feel that this approach may be hazardous. The patient with a large A-V malformation has a wide pulse pressure normally. Even small volume losses in a relatively hypovolaemic patient may cause the diastolic pressure to fall to levels that give inadequate myocardial perfusion, leading to cardiac arrest. Consequently, our approach is to attempt to maintain these patients in a euvolaemic state before clipping and to monitor systolic and diastolic blood pressure closely, using an arterial catheter and pressure transducer. We have not observed the dramatic rise in blood pressure following clipping of the feeders which Takehara, et al. reported. Should myocardial failure occur after clipping of the vessels is completed, we would recommend diuresis and pharmacological afterload reduction rather than the alternative of having the patient hypovolaemic throughout the procedure.

\section{SUMMARY}

All neonates and infants in whom surgery is planned for clipping of a large AVM should have a full cardiac assessment and cardiac failure should be optimally controlled before operation. A large bore intravenous line should be in place before the operation is begun and cross-matched blood should be immediately available. Electrocardiogram, cesophageal stethoscope and an indwelling arterial cannula are essential for monitoring of the cardiovascular system. A central venous line, while useful, may not reflect left ventricular filling pressure accurately, as many of these patients have raised PA pressures.

While furosemide may be given to prevent hypervolaemia and used in conjunction with dexamethasone to minimize cerebral oedema, the patient should be maintained in a euvolaemic state to avoid precipitous falls in blood pressure and, therefore, in diastolic myocardial perfusion.

Although the mortality rate remains high in neonates with arteriovenous malformations of the vein of Galen, we hope that as surgical and anaesthetic experience increases, survival will be improved in those with operable lesions.

\section{REFERENCES}

1. Knuoson, R.P. \& Alden, E.R. Symptomatic arteriovenous malformation in infants less than 6 months of age. Pediatrics $64: 238$ (1979).

2. Amacher, A.L. \& SHILlito, J. JR. The syndromes and surgical treatment of aneurysms of the great vein of Galen. J. Neurosurg. 39: 89 (1973).

3. Gold, A.P., Ransohoff, J. \& Carter, S. Vein of Galen malformation. Acta Neurol. Scand. 40 Suppl. 2 (1964)

4. Holden, A.M., Fyler, D.C., Shillito, J. JR. 
$\&$ NADAS, A.S. Congestive heart failure from intracranial arteriovenous fistula in infancy: Clinical and physiologic considerations in eight patients. Pedjatrics 49: 30 (1972).

5. EIDE, J. \& FøLling, M. Malformation of the great vein of Galen with neonatal heart failure: Report of two cases. Acta Paed. Scand. 67: 529 (1978).

6. RuSSELl, W. \& NEWTON, T. H. Aneurysm of the vein of Galen: Case report and review of the literature. am. J. Roentgenol. 92: 756 (1964).

7. Meridy, H.W., Creighton, R.E. \& HumPHREYS, R.P. Complications during neurosur- gery in the prone position in children. Can. Anaesth. Soc. J. 21: 445 (1974).

8. HoOD, J.B., Wallace, C.T. \& MahafFey, J.E. Anesthetic management of an intracranial arteriovenous malformation in infancy. Anesth. Analg. (Cleve.) 56: 236 (1977).

9. NoRMan, M.G. \& BeCKer, L.E. Cerebral damage in neonates resulting from arteriovenous malformation of the vein of Galen. J. Neurol. Neurosurg. Psychiatry 37: 252 (1974).

10. Takehara, Y., ARakI, S., Motomatsu, K. \& Goya, T. Anesthesia for Galen aneurysm. Masui 28: 738 (1979) (in Japanese, English abstract).

\section{RÉsumÉ}

Les malformations artério-veineuses de l'ampoule de Galien, bien que rares, sont associées avec un taux de mortalité important. La conduite anesthésique nécessitée par la chirurgie de cette condition peut se compliquer d'hémorragie massive et d'insuffisance cardiaque congestive. Quatre jeunes patients de moins de 18 mois on subi des craniotomies pour des malformations artério-veineuses de l'ampoule de Galien. Comme deux de ces patients ont dû subir une deuxième craniotomie pour ligature de vaisseaux nourriciers superficiels on a compté six interventions sur quatre patients. La perte sanguine moyenne par intervention a été évaluée à 126 pour cent du volume sanguin. Un patient est mort pendant l'intervention et un autre a subi un arrêt cardiaque per-opératoire. Deux de ces patients souffraient également d'insuffisance cardiaque. En présence de myocarde défaillant, l'hémorragie subite ou des tentatives d'hypotension contrôlée peuvent causer une perfusion dyastolique inadéquate du cocur et précipiter un arrêt cardiaque. En conséquence ces malades devraient être maintenus dans un état euvolémique avec des transfusions et on devrait éviter toute tentative d'induire l'hypotension contrôlée. 